Published in Mater. Sci. Forum, vols. 217-222, 1996, pp. 795-800

\title{
PRECIPITATION KINETICS OF AN Al-15\%Mg ALLOY STUDIED BY MICROCALORIMETRY AND TEM
}

\author{
M.J. Starink and A.-M. Zahra
}

Centre de Thermodynamique et de Microcalorimétrie du CNRS, 13331 Marseille Cedex 3, France

Keywords: Al-Mg, precipitation, kinetics, calorimetry, activation energy

\section{Abstract}

The kinetics of $\beta^{\prime}$ formation from supersaturated Al-15mass\%Mg solid solutions was studied by microcalorimetry and transmission electron microscopy (TEM). It is shown that the transformation can not be described by the commonly used equation:

$$
\frac{\mathrm{d} \alpha}{\mathrm{dt}}=\mathrm{k}(\mathrm{T}) \mathrm{f}(\alpha)
$$

The function $f(\alpha)$ is different at different temperatures. Apparent activation energies decrease with amount transformed from $1.07 \mathrm{eV}$ to $0.7 \mathrm{eV}$. These findings are discussed in terms of overlapping of the nucleation and growth processes for $\beta^{\prime}$.

\section{Introduction}

Although different symbols for the zones and phases have been used, most work on the precipitation in Al-Mg [1,2,3,4] indicates the following precipitation sequence (symbols as used in Ref. 1):

$$
\text { sss } \alpha \rightarrow \text { GP zones } \rightarrow \beta^{\prime \prime} \rightarrow \beta^{\prime} \rightarrow \beta
$$

where sss $\alpha$ is the supersaturated solid solution, GP zone (also indicated as $\delta^{\prime \prime}$ ) stands for GuinierPreston zone, $\beta^{\prime \prime}$ (other indications: ordered GP zone [5] or $\delta^{\prime}$ ) is an $\mathrm{L} 1_{2}$ ordered phase (composition $\mathrm{Al}_{3} \mathrm{Mg}$ ) [6] appearing as approximately spherical coherent precipitates, $\beta^{\prime}$ is a semicoherent hexagonal intermediate phase (approximate composition $\mathrm{Al}_{3} \mathrm{Mg}_{2}$ ) with lattice parameters $\mathrm{a}=1.002 \mathrm{~nm}$ and $\mathrm{c}=1.636 \mathrm{~nm}$ [4,7], it is the main hardening precipitate [8], and $\beta$ is the equilibrium phase (approximate composition $\mathrm{Al}_{3} \mathrm{Mg}_{2}$ ) having an FCC structure with $\mathrm{a}=2.824 \mathrm{~nm}$ [4,7]. When solid solutions with up to 17 mass\%Mg are aged at temperatures in excess of about $110^{\circ} \mathrm{C}$ no $\mathrm{L}_{2}$ ordered structures or zones form. In solid-quenched and liquid-quenched Al-Mg aged between about $110^{\circ} \mathrm{C}$ and $250^{\circ} \mathrm{C}$ the $\beta^{\prime}$ phase forms first and the $\beta$ phase only appears in the later stages of ageing when the $\mathrm{Mg}$ depletion of the matrix is nearly completed $[4,9]$.

In the present work the kinetics of precipitation in an Al-15mass\%Mg alloy was studied by TEM and microcalorimetry. The latter technique allows the determination of the progress of the reaction at constant temperature with a very high precision.

\section{Experimental}

A high purity alloy with nominal composition Al-15Mg was produced by conventional casting and subsequent rolling at Centre de Recherches de Voreppe (Aluminium Pechiney). Chemical analysis revealed the composition $14.5 \pm 0.2$ mass \% Mg (corresponding to 15.8 at \%), with typical total impurity content about 0.03 mass \% (mainly $\mathrm{Si}$ ). The grain size is very large: about 1 to $2 \mathrm{~mm}$. 
For each calorimetric experiment the same batch of 20 disk shaped samples of $1 \mathrm{~mm}$ thickness was used. A differential Tian-Calvet microcalorimeter with two furnaces fixed above it combined with an automatic introduction system was employed. The sample batch was solution treated at $440^{\circ} \mathrm{C}$ for $2 \mathrm{~h}$ in the top furnace and subsequently lowered into the lower furnace. The set temperature of this furnace $\left(20^{\circ} \mathrm{C}\right.$ below the calorimeter temperature) and the hold time of the sample (about 150 s) were chosen such that the sample reached a temperature close to the calorimeter temperature. The calorimeter used for the subsequent isothermal heat flow experiment possesses an excellent base line stability coupled with a high sensitivity (down to a microwatt). Ageing temperatures between 130 and $260^{\circ} \mathrm{C}$ at intervals of $10^{\circ} \mathrm{C}$, and times up to 7 days were employed. Due to the insertion of the specimen the heat flow measurement in the calorimeter is initially disturbed, and the heat flow due to the transformation in the sample can not be measured during the first 20 min. Generally 3 experiments per temperature were performed; the reproducibility of the heat flow and of the time at maximum exothermic heat flow are both typically about $1 \%$. The baseline of the microcalorimeter at each temperature was determined by performing experiments with pure $\mathrm{Al}$.

For TEM experiments samples were heat treated in the calorimeter according to the above described procedure and were subsequently stored in liquid nitrogen. The specimens were ground to about $100 \mu \mathrm{m}$ and electropolished in a 3:1 mixture of methanol and $\mathrm{HNO}_{3}$ at $-20^{\circ} \mathrm{C}$. The foils were examined in a Philips EM 400 T microscope operated at $100 \mathrm{kV}$ and a JEOL JEM $2010 \mathrm{~J}$ microscope operated at $200 \mathrm{kV}$.

\section{Results and discussion}

\subsection{TEM}

Consistent with its published limits of stability [1] no superspots due to an $\mathrm{L} 1_{2}$ ordered phase were noted in the selected area diffraction (SAD) patterns obtained at the temperatures studied $\left(\mathrm{T} \geq 130^{\circ} \mathrm{C}\right.$ ) and only $\beta$ ' and $\beta$ was observed. The $\beta$ ' phase was identified by its characteristic SAD pattern in the Al [110] direction (compare Fig. 1 with Fig. 1 in Ref. 7). The characteristic microstructure of the $\mathrm{Al}-15 \mathrm{Mg}$ samples aged at 130 and $190^{\circ} \mathrm{C}$ to the peak of the exothermic effect consists of lath-like $\beta$ ' precipitates with slightly irregular shapes (see Fig. 2) and hardly any $\beta$ phase. Only after $17.5 \mathrm{~h}$ at $190^{\circ} \mathrm{C}$ significant amounts ( a few percent of the $\beta$ ' volume) were observed. This late appearance of the equilibrium $\beta$ phase (at this stage about $84 \%$ of the total heat evolution is completed) is consistent with results obtained by Bernole [4]. Special attention was paid to check for $\beta$ phase growing on the $\beta$ ' particles; only for a small minority of $\beta$ this appeared to be the case.

Consistent with the large grain size very few grain boundaries were observed in TEM foils, some contained continuous $\beta$ phase precipitates.

\subsection{Calorimetry}

All calorimetric experiments show a single exothermic heat effect with a single peak. In Fig. 3 several normalised heat flow curves are presented. In order to characterise these curves, theoretical ones as described by the following equations were used for fitting:

$$
\begin{aligned}
& \frac{\mathrm{d} \alpha}{\mathrm{dt}}=\mathrm{k}(\mathrm{T}) \mathrm{f}(\alpha) \\
& \mathrm{f}(\alpha)=(1-\alpha)^{\mathrm{p}}\left[\ln \frac{1}{(1-\alpha)}\right]^{\mathrm{q}}
\end{aligned}
$$


Fig. 1 SAD pattern of matrix with $\beta$, precipitates as depicted in Fig. 2. Orientation is close to $\mathrm{Al} \mathrm{[110].}$
Fig. 2 TEM micrograph of Al-15Mg aged for 4d at $130^{\circ} \mathrm{C}$ (maximum of exothermic heat flow). Bright Field. B close to Al [110].

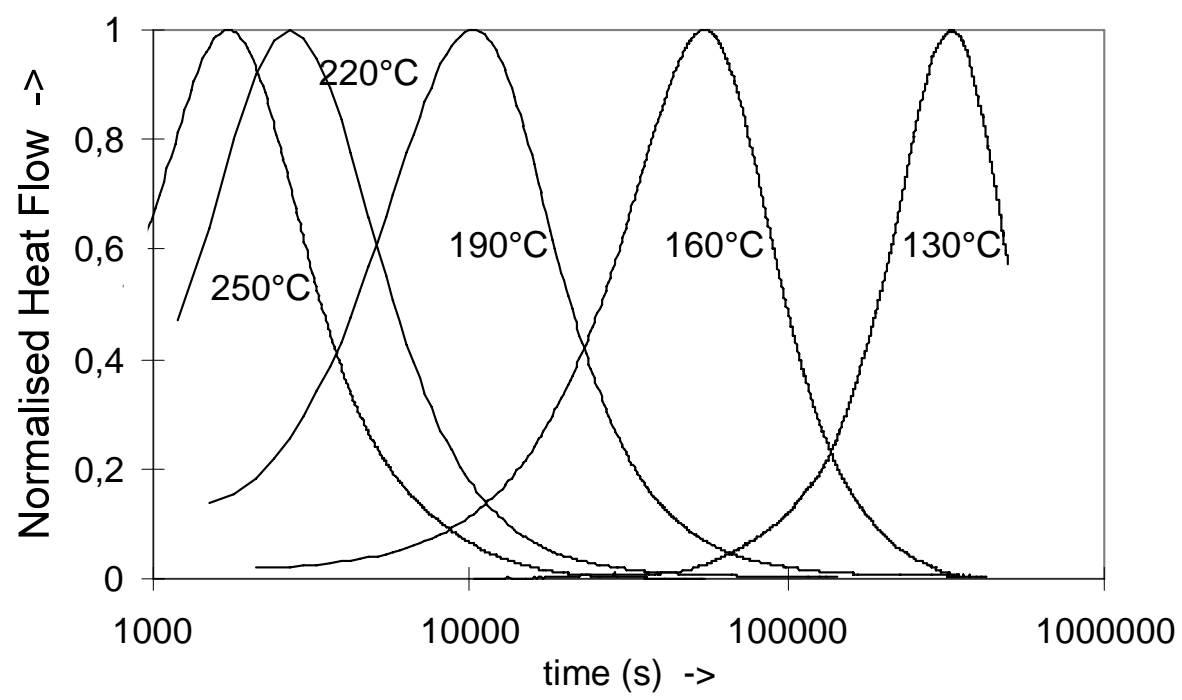

Fig. 3: Normalised exothermic heat flow during isothermal ageing of the Al-15Mg alloy.

where $\alpha$ is the fraction transformed, i.e.

$$
\alpha=x(t) / x(t \rightarrow \infty, T)
$$

$f(\alpha)$ is a function depending only on the fraction transformed, $k(T)$ is a function of temperature, $\mathrm{x}(\mathrm{t})$ is the amount precipitated (proportional to the heat evolved), $\mathrm{x}(\mathrm{t} \rightarrow \infty, \mathrm{T})$ is the maximum amount precipitated (i.e. the total heat released). It is noted that this choice for $f(\alpha)$ (Eq. 2) can take account of both homogeneous $n$-th order reaction kinetics $(q=0$, reaction order $n=p)$ and JohnsonMehl-Avrami (JMA) reaction kinetics ( $p=1$ and Avrami exponent $\left.m=(1-q)^{-1}\right)$. The fitting resulted in curves which match the experimental ones closely (see Fig. 4), but only providing that the coefficients $p$ and $q$ were allowed to vary with temperature. At this stage $k(T)$ was allowed to vary freely with temperature. The obtained values for $\mathrm{p}$ and $\mathrm{m}$ (Fig. 5) correspond neither to homogeneous reaction kinetics nor, as $\mathrm{p}$ is always significantly larger than 1 , to JMA reaction kinetics. 


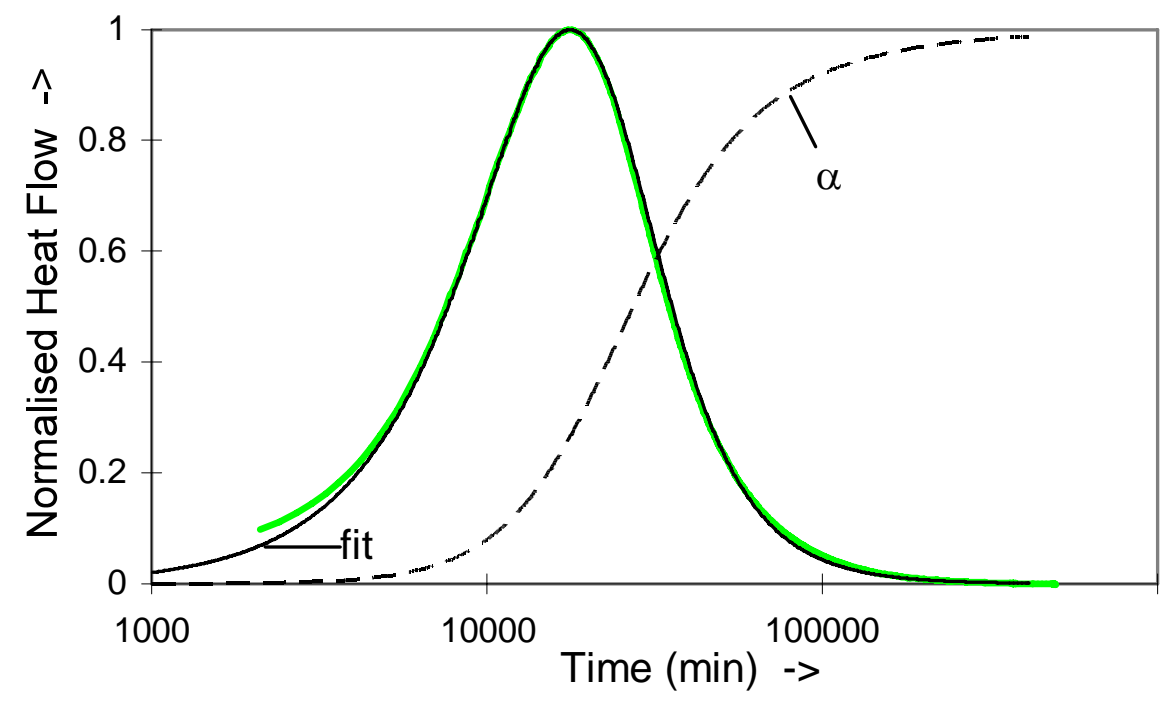

Fig. 4 Measured normalised exothermic heat flow during ageing at $180^{\circ} \mathrm{C}$ and the fitted curve based on Eqs. 1 and $2(\mathrm{~m}=2.6, \mathrm{p}=2)$. Also $\alpha$ obtained from the fitted curve is presented.

The fitted curves were used to extrapolate the transformation curves into regions where no heat flow measurements were performed ( $\mathrm{t}>7$ days) or could be performed $(\mathrm{t}<20 \mathrm{~min})$, and the total heat released, $\Delta \mathrm{H}_{\text {tot }}$, was calculated. In Fig. 6 both $\Delta \mathrm{H}_{\text {tot }}$ and the heat released up until the maximum of the exothermic heat flow, $\Delta \mathrm{H}_{\text {peak }}$, are presented. It is observed that $\Delta \mathrm{H}_{\text {peak }}$ slightly decreases with $\mathrm{T}$ up to about $220^{\circ} \mathrm{C}$. This is thought to be due to a slight decrease in the amount of $\beta$ ' formed at this stage as a result of the increase of (metastable) Mg solubility. The observed increase of $\Delta \mathrm{H}_{\text {tot }}$ up until $210^{\circ} \mathrm{C}$ is thought to be due to a gradual increase of the ratio of $\beta$ to $\beta$, formed during the experiment. The subsequent decrease beyond $210^{\circ} \mathrm{C}$ is ascribed to an increase of the Mg solubility.

The extrapolations indicate that two minutes ageing at the temperature of maximum transformation rate (about $260^{\circ} \mathrm{C}$, see Ref. 3) corresponds to about $610^{-5}$ of the total heat production. Hence the amount of transformation occurring during the cooling before introduction into the calorimeter is negligible and the chosen set temperature of the furnace in which the specimen is cooled prior to introduction is thought to be largely irrelevant. Additional experiments with two set temperatures of the furnace $\left(100\right.$ and $170^{\circ} \mathrm{C}$ ) followed by ageing at $190^{\circ} \mathrm{C}$ confirmed this: it was found that the time at maximum heat evolution was constant within $0.3 \%$ whilst the total measured heat evolution was constant within $2 \%$. Also reported activation energies (see below) are hardly influenced.

\subsection{Kinetic analysis}

In kinetic analysis it is usually assumed that $\mathrm{k}(\mathrm{T})$ as defined in Eq. 1 is given by the Arrhenius expression, i.e.

$$
k(T)=k_{0} \exp \left(-E / k_{B}\right)
$$

$\mathrm{E}$ being the activation energy of the reaction, $\mathrm{k}_{\mathrm{B}}$ Boltzmann's constant, and $\mathrm{k}_{\mathrm{o}}$ a preexponential factor. Although Eq. 1 appears to hold well for a large number of thermally activated reactions, there is no direct theoretical justification for its general validity. The main assumption made when using Eq. 1 is that the dependency of the reaction rate can be described as two separate functions one of which depends on $\mathrm{T}$ and the other on $\alpha$. Hence the activation energy should not depend on $\alpha$, whilst the transformation function $\mathrm{f}(\alpha)$ should not depend on the temperature. In case that the 


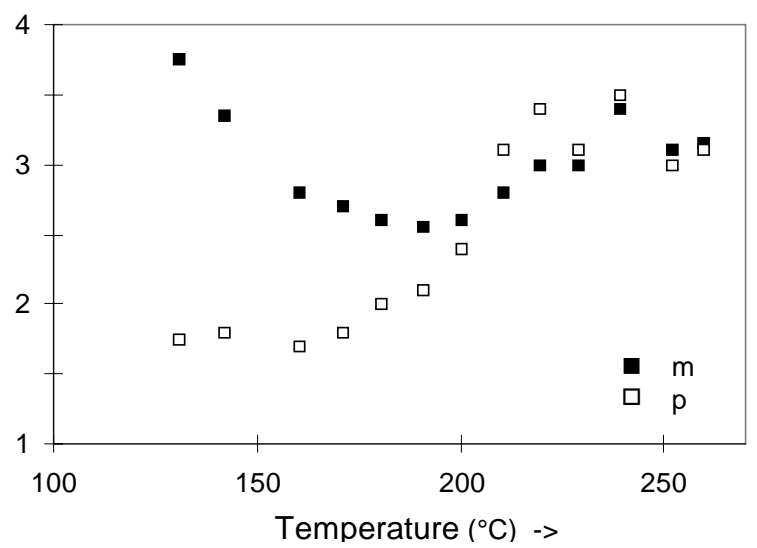

Fig. 5 Coefficients $m=(1-q)^{-1}$ and $p$ used for fitting of isothermal ageing curves.

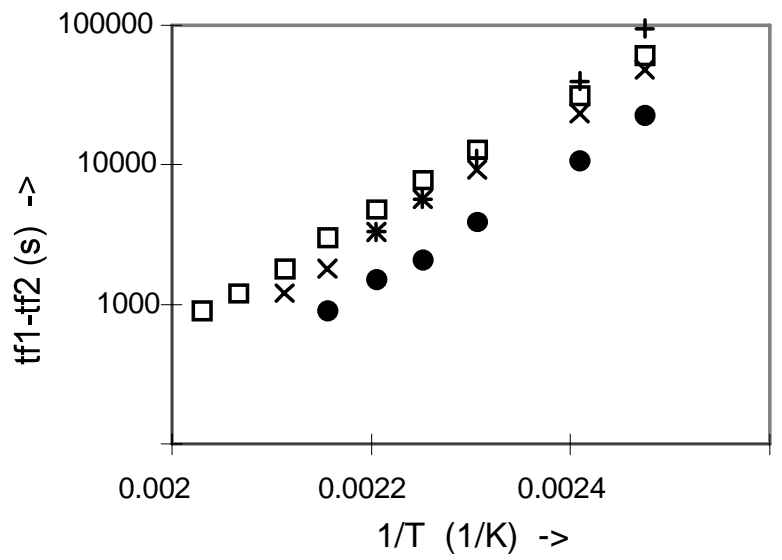

Fig. 7 Plots of $\log \left(\mathrm{t}_{\mathrm{f} 1}-\mathrm{t}_{\mathrm{f} 2}\right)$ vs. $1 / \mathrm{T}$ for different stages of the reaction. $+10 \mathrm{~J} / \mathrm{mol}$ evolved, -30 to $50 \mathrm{~J} / \mathrm{mol}, 5100$ to $200 \mathrm{~J} / \mathrm{mol}, \square 0.5$ to $1 \mathrm{~kJ} / \mathrm{mol}$.

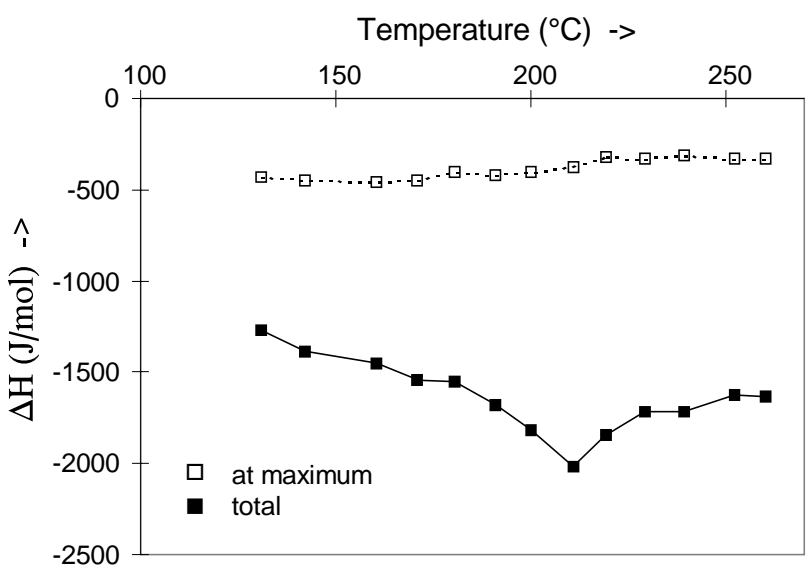

Fig. 6 Total evolved heat during isothermal ageing and the heat evolved at the maximum exothermic heat flow.

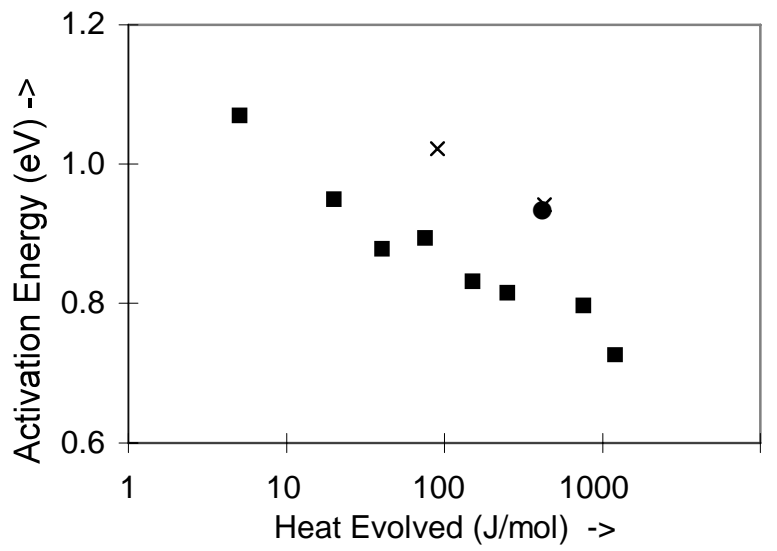

Fig. 8 Apparent activation energy vs. heat evolved. Fixed stages were defined by 10,30 , 50, 100, 200, 300, 500, 1000 and $1500 \mathrm{~J} / \mathrm{mol}$ evolved heat $(v)$, or as the peak $(\bullet)$ or half peak heat production (5).

transformation experiments are performed at constant temperature it follows from Eqs. 1 and 4:

$$
\ln \left(\mathrm{t}_{\mathrm{f} 2}-\mathrm{t}_{\mathrm{f} 1}\right)=\frac{\mathrm{E}}{\mathrm{k}_{\mathrm{B}} \mathrm{T}}+\mathrm{C}_{1}
$$

where $t_{f 1}, t_{f 2}$ are times at which fixed stages of the reaction are obtained, $C_{1}$ is a constant. Hence the slope of the straight line through a plot of $\ln \left(\mathrm{t}_{\mathrm{f} 1}-\mathrm{t}_{\mathrm{f} 2}\right)$ vs. $1 / \mathrm{T}$ yields the activation energy. In Fig. 7 several such plots are presented for the Al-15Mg alloy. It is noted that the plots are linear only below a certain temperature (about $190^{\circ} \mathrm{C}$ ), and that the activation energies as obtained from the slopes of the straight lines vary with the amount of heat evolved (see Fig. 8). An overlap of $\beta$ with $\beta^{\prime}$ precipitation can not explain the latter as: i) the formation of the stable $\beta$ phase will have a higher activation energy than $\beta^{\prime}$ precipitation and ii) TEM work indicates that very little $\beta$ precipitation occurs in the time and temperature range where $\mathrm{E}_{\text {app }}$ decreases. The non-linearity of the plots at $\mathrm{T}>190^{\circ} \mathrm{C}$ is ascribed to the increase in solubility of $\mathrm{Mg}$ with increasing temperature. 
The resulting decrease of $x(t \rightarrow \infty, T)$ with increasing $T$ will render the definition of the fraction transformed problematic: a constant $\alpha$ no longer signifies a constant amount of $\beta$ ' formed. Hence Eq. 5 is not valid.

The results presented indicate that the precipitation kinetics in the Al-15Mg alloy do not conform to Eq. 1. It is noted that also concentration profiles of $\mathrm{Mg}$ in the matrix next to the precipitates in Al-9at\%Mg differ from those expected from classical growth by diffusion models: it appears [10] that while the precipitate ${ }^{*}$ grows during ageing at $150^{\circ} \mathrm{C}$ the concentration profile normal to the precipitate hardly changes. Yukawa et al. [10] further noted that even in overaged Al-Mg alloys the $\mathrm{Mg}$ concentration in the matrix between precipitates remains relatively high. Also this is unusual for classical growth by diffusion models. It is here suggested that these observations may be related to a reduced vacancy concentration and consequently a low diffusion coefficient in the vicinity of the precipitate. This reduced vacancy concentration may result from i) a reduced capacity of vacancy retention due to the reduction of the $\mathrm{Mg}$ concentration in that area ( $\mathrm{Mg}$ atoms have a strong binding to vacancies), ii) capture of vacancies in the precipitate, and/or iii) annihilation of vacancies at the precipitate/matrix interface. The low vacancy concentration would generally hamper the growth of the precipitates and result in a steep and stable $\mathrm{Mg}$ concentration gradient around the precipitate. It is envisaged that as a result of this the nucleation of precipitates plays a significant role during most of the decomposition process. The observed variation of the apparent activation energy with amount transformed (see Fig. 8) may then due to the decomposition process gradually changing from nucleation dominated to growth dominated. Further research into this is currently underway.

\section{Conclusions}

Analysis of isothermal calorimetry data shows that the precipitation kinetics in the Al-15Mg alloy do not conform to Eq. 1 as: i) the transformation function $f(\alpha)$ varies significantly with temperature, and ii) apparent activation energies, $E_{\text {app }}$, decrease with fraction transformed (Fig. 8). It is thought that nucleation of precipitates plays a significant role in the transformation process even until the transformation is nearing its completion

\section{Acknowledgements}

This work is financed in part by the EC Human Capital and Mobility project. The authors are grateful to C. Zahra for technical assistance and to Dr. A. Charaï of CP2M, Université d'AixMarseille III, for making available TEM facilities.

\section{References}

$1 \quad$ K. Osamura and T. Ogura, Metall. Trans. 15A, 835 (1984)

2 A. Dauger, E.K. Boudili and M. Roth, Scr. Metall. 10, 1119 (1976)

3 R. Nozato and S. Ishihara, Trans. Japan. Inst. 21, 580 (1980)

$4 \quad$ M. Bernole, Thesis at the University of Rouen, 1974

5 A. Dauger, M. Fumeron, J.P. Guillot and M. Roth, J. Apll. Cryst. 12, 429 (1979)

6 T. Sato, Y Kojima and T. Takahashi, Metall. Trans. 13A, 1373 (1982)

$7 \quad$ M. Bernole, J. Raynal and R. Graf, J. de Microscopie 8, 831 (1969)

8 S. Nebti, D. Hamana and G. Cizeron, Acta Metall. Mater. 43, 3583 (1995)

9 P. van Mourik, N.M. Maaswinkel, Th.H. de Keijser and E.J. Mittemeijer, J. Mater. Sci. 24, 3779 (1989).

10 H. Yukawa, Y. Murata, M. Morinaga, Y. Takahashi and H. Yoshida, Acta Metall. Mater. 43, 681 (1995)

\footnotetext{
Yukawa et al. [10] consistently indicate the precipitates in their Al-9at\% Mg alloy as being the equilibrium $\beta$ phase. As they do not present an identification of the precipitates concerned and as the present work and other publications [4,7] all indicate that the precipitates formed in similar alloys are mainly $\beta^{\prime}$ phase, it is thought that the precipitates studied by Yukawa et al. are in fact $\beta^{\prime}$.
} 